\title{
Clostridium hastiforme is a later synonym of Tissierella praeacuta
}

\author{
Jin-Woo Bae, ${ }^{1}$ Ja Ryeong Park, ${ }^{1}$ Young-Hyo Chang, ${ }^{1}$ Sung-Keun Rhee, ${ }^{1}$ \\ Byung-Chun $\mathrm{Kim}^{1}$ and Yong-Ha Park ${ }^{1,2}$ \\ ${ }^{1}$ Korea Research Institute of Bioscience and Biotechnology (KRIBB), PO Box 115, Yusong, \\ Daejon, Korea \\ ${ }^{2}$ National Research Laboratory of Molecular Ecosystematics, Institute of Probionic, Probionic \\ Corporation, Bio-venture Center, KRIBB, PO Box 115, Yusong, Daejon, Korea
}

Correspondence

Yong-Ha Park

yhpark@kribb.re.kr

\begin{abstract}
The previously proposed species Clostridium hastiforme and Tissierella praeacuta appear to be similar from their published descriptions. Accordingly, the aim of the current study was to perform phenotypic and genetic analyses of the type strains of both species, in order to clarify their taxonomic positions. The type strains of C. hastiforme (DSM $\left.5675^{\top}\right)$ and T. praeacuta (NCTC $11158^{\top}$ ) exhibited identical biochemical profiles and their $16 \mathrm{~S}$ rRNA gene sequences displayed $99.9 \%$ similarity. DNA-DNA hybridization was also estimated to be $96.5 \%$. Thus, it was concluded that $C$. hastiforme and $T$. praeacuta are synonyms, where $T$. praeacuta has priority. An emended description of the genus Tissierella is also given.
\end{abstract}

Clostridium hastiforme MacLennan $1939^{\mathrm{AL}}$ (type strain, ATCC $33268^{\mathrm{T}}=$ VPI $12193^{\mathrm{T}}=\mathrm{DSM} 5675^{\mathrm{T}}$ ) was suggested for the organism that was described by Cunningham as bacillus $4 \mathrm{a}$, which is typically a slender, rod-shaped organism with rounded ends, $0 \cdot 3-0.6 \times 2-6 \mu \mathrm{m}$ in size (MacLennan, 1939). In addition, this terminally spored anaerobe does not ferment carbohydrates and is sluggishly motile, due to numerous peritrichous flagella. It has also been reported that $C$. hastiforme is similar to Clostridium subterminale, except that the spores are terminal and no hydrogen is produced (Cato et al., 1982; Holdeman et al., 1991). Cato et al. (1982) used protein electrophoresis as a tool to distinguish these two species. Suen et al. (1988) reported the DNA-DNA relatedness of strains that were identified initially as $C$. hastiforme and divided several strains into Clostridium argentinense, Clostridium botulinum, Clostridium sporogenes, C. subterminale and C. hastiforme. A corresponding phenotypic differentiation study between C. hastiforme and C. subterminale was also reported by Niel et al. (1989), based on analysing the reduced-pressure headspaces from $168 \mathrm{~h}$ cultures with GC, which showed that strain ATCC 25772 (=DSM 1786), previously identified as C. hastiforme, was neither a $C$. hastiforme strain nor a C. subterminale strain. Collins et al. (1994) reported that $C$. argentinense, C. botulinum, C. sporogenes and C. subterminale all belong to cluster I of the clostridia, whereas C. hastiforme is within group XII, indicating that C. hastifome is not a 'real' Clostridium species.

Farrow et al. (1995) indicated that the 16S rRNA gene

Published online ahead of print on 9 January 2004 as DOI 10.1099/ ijs.0.63068-0. sequence of Gram-negative, non-spore-forming Tissierella praeacuta (NCTC $11158^{\mathrm{T}}$ ) was almost identical to the sequence of Gram-positive, spore-forming C. hastiforme. They also compared the $16 \mathrm{~S}$ rDNA sequences of both strains held in other collections to eliminate any possibility of incorrect strain designation or culture contamination. In current bacterial systematics, a bacterial species is defined as a group of strains that exhibit $\geqslant 70 \%$ DNA-DNA relatedness at an optimal incubation temperature (Wayne et al., 1987), together with phylogenetic inference based on $16 \mathrm{~S}$ rDNA sequence comparison. Therefore, the aims of the present study were to determine the levels of DNA-DNA relatedness between $C$. hastiforme and T. praeacuta and to determine whether the current taxonomic status of each species is correct.

The type strains of $T$. praeacuta $\left(\right.$ ATCC $25539^{\mathrm{T}}=$ NCTC $11158^{\mathrm{T}}=\mathrm{NCIMB} 703038^{\mathrm{T}}$ ) and $C$. hastiforme (ATCC $33268^{\mathrm{T}}=\mathrm{NCTC} 11832^{\mathrm{T}}=$ DSM $\left.5675^{\mathrm{T}}\right)$ were obtained from the NCIMB (National Collections of Industrial Food and Marine Bacteria, London, UK) and DSMZ (Deutsche Sammlung von Mikroorganismen und Zellkulturen, Braunschweig, Germany), respectively. The strains were cultured as recommended by the respective culture collections. Shape and size of living and stained cells were determined by light microscopy. Gram reaction was determined by using a Gram-stain kit (Difco), according to the manufacturer's recommended protocol. To distinguish false-negative Gram-staining, a $\mathrm{KOH}$ test was performed in parallel with the Gram-stain reaction, based on mixing a visible amount of growth from a colony in a loopful of $3 \%$ aqueous $\mathrm{KOH}$ on a glass slide (Powers, 1995). Enzyme profiles were generated for each strain by using API 
ZYM kits (bioMérieux) according to the manufacturer's instructions. Cellular fatty acid composition was determined by using the method of Suzuki \& Komagata (1983). Chromosomal DNA was isolated and purified according to a method described previously (Yoon et al., 1996). DNADNA hybridization was carried out according to the method of Ezaki et al. (1989). 16S rDNA was amplified by PCR using two universal primers, as described previously (Yoon et al., 1998). The PCR product was purified by using a QIAquick PCR purification kit (Qiagen). The purified 16S rDNA was then sequenced by using an ABI PRISM BigDye Terminator Cycle Sequencing Ready Reaction kit (Applied Biosystems), as recommended by the manufacturer. Purified sequencing reaction mixtures were electrophoresed automatically by using an Applied Biosystems model 310 automatic DNA sequencer. $16 \mathrm{~S}$ rDNA sequence alignment and phylogenetic tree construction were conducted by using CLUSTAL $\mathrm{X}$ software (Thompson et al., 1997).

DNA-DNA hybridization was performed to determine genomic relatedness between the type strains of $T$. praeacuta and $C$. hastiforme; as their DNA-DNA relatedness was $96.5 \%$, they seem to be members of the same genomic species (Wayne et al., 1987). T. praeacuta and C. hastiforme were also found to be indistinguishable based on their biochemical characteristics. Both type strains exhibited approximately the same enzymic activity of esterase (C4), leucine arylamidase, acid phosphatase and naphthol-AS-BIphosphohydrolase by using an API ZYM test kit. Contrary to a previous report, $T$. praeacuta tested Gram-positive; the $\mathrm{KOH}$ test also confirmed that $T$. praeacuta and $C$. hastiforme were both Gram-positive species. As such, it is possible that the previous result for T. praeacuta was false-negative Gramstaining that occurred with a long incubation time (Powers, 1995). The major cellular fatty acids for both strains were iso- $\mathrm{C}_{15: 0}\left(22 \cdot 3-23 \cdot 4 \%\right.$ total cellular fatty acids) and $\mathrm{C}_{16: 0}$ $(12 \cdot 5-12 \cdot 7 \%$ total cellular fatty acids). Thus, it was evident from the polyphasic taxonomic study that the type strains of T. praeacuta and C. hastiforme belong to the same species.

The species $T$. praeacuta was originally isolated by Tissier (1908). After a long, unsettled taxonomic history (Farrow et al., 1995), Collins \& Shah (1986) reclassified Bacteroides praeacutus Tissier in a novel genus, Tissierella. So far, three species have been assigned to the genus Tissierella, i.e. T. praeacuta, Tissierella creatinini and Tissierella creatinophila. On the basis of the phylogenetic tree constructed by Harms et al. (1998), T. praeacuta and C. hastiforme were related most closely to $T$. creatinini and $T$. creatinophila, and all tested Gram-positive. Accordingly, it is proposed that C. hastiforme MacLennan $1939^{\mathrm{AL}}$ is a later synonym of T. praeacuta. Therefore, an emended description of the genus Tissierella is given below.

\section{Emended description of the genus Tissierella}

The characteristics of the genus are as described by Collins \& Shah (1986), except that cells are all Gram-positive and D-ornithine and meso-diaminopimelic acid are present in the peptidoglycan. Some species possess malate dehydrogenase and glutamate dehydrogenase activity.

\section{Acknowledgements}

This work was supported by grant BDM0200211 from the Korean Ministry of Science and Technology (MOST).

\section{References}

Cato, E. P., Hash, D. E., Holdeman, L. V. \& Moore, W. E. C. (1982). Electrophoretic study of Clostridium species. J Clin Microbiol 15, 688-702.

Collins, M. D. \& Shah, H. N. (1986). Reclassification of Bacteroides praeacutus Tissier (Holdeman and Moore) in a new genus, Tissierella, as Tissierella praeacuta comb. nov. Int J Syst Bacteriol 36, 461-463.

Collins, M. D., Lawson, P. A., Willems, A., Cordoba, J. J., FernandezGarayźabal, J., Garcia, P., Cai, J., Hippe, H. \& Farrow, J. A. E. (1994). The phylogeny of the genus Clostridium: proposal of five new genera and eleven new species combinations. Int J Syst Bacteriol 44, 812-826.

Ezaki, T., Hashimoto, Y. \& Yabuuchi, E. (1989). Fluorometric deoxyribonucleic acid-deoxyribonucleic acid hybridization in microdilution wells as an alternative to membrane filter hybridization in which radioisotopes are used to determine genetic relatedness among bacterial strains. Int J Syst Bacteriol 39, 224-229.

Farrow, J. A. E., Lawson, P. A., Hippe, H., Gauglitz, U. \& Collins, M. D. (1995). Phylogenetic evidence that the gram-negative nonsporulating bacterium Tissierella (Bacteroides) praeacuta is a member of the Clostridium subphylum of the gram-positive bacteria and description of Tissierella creatinini sp. nov. Int J Syst Bacteriol 45, 436-440.

Harms, C., Schleicher, A., Collins, M. D. \& Andreesen, J. R. (1998). Tissierella creatinophila sp. nov., a Gram-positive, anaerobic, nonspore-forming, creatinine-fermenting organism. Int J Syst Bacteriol 48, 983-993.

Holdeman, L. V., Cato, E. P. \& Moore, W. E. C. (1991). Anaerobe Laboratory Manual, 4th edn. Blacksburg, VA: Virginia Polytechnic Institute and State University.

MacLennan, J. D. (1939). The non-saccharolytic plectridial anaerobes. J Pathol Bacteriol 49, 535-548.

Niel, P., Rimbault, A., Campion, G. \& Leluan, G. (1989). Phenotypic differentiation between Clostridium hastiforme and Clostridium subterminale by headspace gas chromatography. Int J Syst Bacteriol 39, 491-492.

Powers, E. M. (1995). Efficacy of the Ryu nonstaining $\mathrm{KOH}$ technique for rapidly determining gram reactions of food-borne and waterborne bacteria and yeasts. Appl Environ Microbiol 61, 3756-3758.

Suen, J. C., Hatheway, C. L., Steigerwalt, A. G. \& Brenner, D. J. (1988). Clostridium argentinense sp. nov.: a genetically homogeneous group composed of all strains of Clostridium botulinum toxin type $\mathrm{G}$ and some nontoxigenic strains previously identified as Clostridium subterminale or Clostridium hastiforme. Int J Syst Bacteriol 38, 375-381.

Suzuki, K. \& Komagata, K. (1983). Taxonomic significance of cellular fatty acid composition in some coryneform bacteria. Int J Syst Bacteriol 33, 188-200.

Thompson, J. D., Gibson, T. J., Plewniak, F., Jeanmougin, F. \& Higgins, D. G. (1997). The CLUSTAL_X windows interface: flexible strategies for multiple sequence alignment aided by quality analysis tools. Nucleic Acids Res 25, 4876-4882. 
Tissier, H. (1908). Recherches sur la flore intestinale normale des enfants âgés d'un à cinq ans. Ann Inst Pasteur (Paris) 22, 189-208 (in French).

Wayne, L. G., Brenner, D. J., Colwell, R. R. \& 9 other authors (1987). International Committee on Systematic Bacteriology. Report of the ad hoc committee on reconciliation of approaches to bacterial systematics. Int J Syst Bacteriol 37, 463-464.
Yoon, J.-H., Kim, H., Kim, S.-B., Kim, H.-J., Kim, W. Y., Lee, S. T., Goodfellow, M. \& Park, Y.-H. (1996). Identification of Saccharomonospora strains by the use of genomic DNA fragments and rRNA gene probes. Int J Syst Bacteriol 46, 502-505.

Yoon, J.-H., Lee, S. T. \& Park, Y.-H. (1998). Inter- and intraspecific phylogenetic analysis of the genus Nocardioides and related taxa based on 16S rDNA sequences. Int J Syst Bacteriol 48, 187-194. 